\title{
Primary cesarean section in multigravidae: a case control study
}

\author{
Madhva Prasad S.*, Anahita R. Chauhan \\ Department of Obstetrics and Gynecology, Seth GS Medical college and KEM Hospital, Mumbai, India
}

Received: 22 April 2017

Accepted: 18 May 2017

\section{*Correspondence:}

Dr. Madhva Prasad S.,

E-mail: madhva@gmail.com

Copyright: (C) the author(s), publisher and licensee Medip Academy. This is an open-access article distributed under the terms of the Creative Commons Attribution Non-Commercial License, which permits unrestricted non-commercial use, distribution, and reproduction in any medium, provided the original work is properly cited.

\section{ABSTRACT}

Background: Primary Cesarean Section (CS) is defined as CS in a patient who has not had a prior CS. While primigravidae contribute to the bulk of those undergoing primary $\mathrm{CS}$, multigravidae (with only prior vaginal delivery) can also contribute. The purpose of this article is to examine the contribution of the group of multigravidae (with only prior vaginal delivery) and how they differ from primigravidae.

Methods: A review of records was conducted for one year period. The confinements which were first or second para (which had undergone CS in either index pregnancy or previous pregnancy) were divided into primipara: primary CS and second para: primary CS. Various parameters were compared between the primipara undergoing primary CS and multipara undergoing primary CS.

Results: Out of 1154 births, the number of CS was 401. Primary CS in primiparas was $266(66.3 \%)$ and primary CS in multipara (with only prior vaginal deliveries) was 61(15.2\%). Booking status, baby weights and NICU admission rates did not different significantly. Preterm deliveries, higher number of prior abortions; malpresentations, deep transverse arrest, antepartum hemorrhage was more common among the multipara group and the difference was statistically significant ( $\mathrm{p}$ value $<0.05$ ).

Conclusions: Multipara (with prior vaginal delivery only) definitely contribute to primary CS rate and cannot be neglected. The profile of patients and the indications of CS in multipara appear to differ from those in primipara.

Keywords: Cesarean section rates, Delivery modes, Multigravidae

\section{INTRODUCTION}

Lower segment cesarean section (CS) is a commonly performed operative procedure in modern medicine, the rates of which are increasing. From 1990 to 2014, the overall worldwide absolute increase in the CS rate was $12.4 \%$ with an estimated average annual increase in rate of around $4.4 \%$. This alarming scenario which has gained the attention of obstetricians, healthcare providers and planners alike, is justified. However, attaining lower cesarean section rates should not cause patient neglect. While all possible perspectives for reduction of cesarean rates should be encouraged, the WHO states specifically that every effort should be made to provide caesarean sections to women in need, rather than striving to achieve a specific rate. ${ }^{1,2}$

Primary CS is defined as CS performed in a patient who has not undergone any prior cesarean section. A lot of emphasis has been placed on the concept of Vaginal Birth after Cesarean and of CS in general. However, the group of multigravida patients (with prior vaginal delivery only) undergoing primary $\mathrm{CS}$ has not received particular attention. In this context, the specific objectives of the study were to examine the differences in various parameters between those undergoing CS with no prior vaginal delivery and those with prior vaginal deliveries. 
The patients can be broadly divided as Group 1: primipara. (Includes $\mathrm{G} 2 \mathrm{~A} 1, \mathrm{G} 3 \mathrm{~A} 2$ etc) primary $\mathrm{CS}$; and Group 2: second para: primary CS. (includes G2P1L1 or G3P1L1A1, G4P1L1A2 etc.). It is proposed that an easily recognizable terminology for patients belonging to this group is CBAV (cesarean birth after vaginal birth).

It was hypothesized that the nature of indications for which CS was performed between the two groups would be different, and other possible associated factors would be responsible for the same.

\section{METHODS}

A retrospective case control study involving review of records for a period of one year was conducted in the obstetric department of a general hospital. Postnatal patients who have undergone $\mathrm{CS}$ in either the index pregnancy studied or previous pregnancy were included. The data was obtained from the labor ward register and the medical records department. There was no interaction with patients and no consents were taken. A single investigator recorded all the data to ensure the uniformity of data collection. Relevant data including age, parity index, previous obstetric history, medical high risks were noted. Indications for CS were noted. Only patients delivering beyond 28 weeks of gestation in the hospital during the time period were included. Patients with two or more prior vaginal deliveries and twin deliveries were excluded. The patients were stratified into the patients undergoing CS into three groups based on their parity index and outcomes as described above. The different indication for which CS was performed was compared between the groups.

\section{Statistical analysis}

Percentage calculations and student t-tests were used for analysis of data. Pearson's chi-square value was used to calculate $\mathrm{p}$-value and statistical significance between groups were analysed.

\section{RESULTS}

All data was obtainable and there was no missing data encountered.

Figure 1 shows the number of confinements ( $>28$ weeks of gestation) during the study period was 1416 , wherein the number of vaginal deliveries (including instrumental deliveries) was 941. The remaining was CS which amounted to 475 , with a CS rate of $33.54 \%$.

Figure 2 shows that the total number of confinements in the study was 1416 . Out of this 262 were of birth order 3 or above, and were excluded. Among the first and second gravid patients (1154 patients), there were 753 vaginal deliveries and $401 \mathrm{CS}$. This group was taken for analysis. It is to be noted that among the 753 vaginal deliveries, 28 were VBAC.

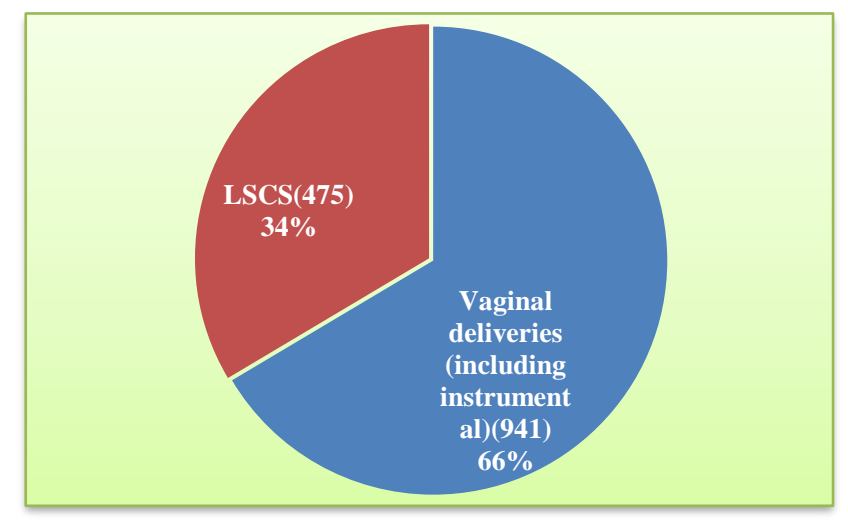

Figure 1: Confinement detail.

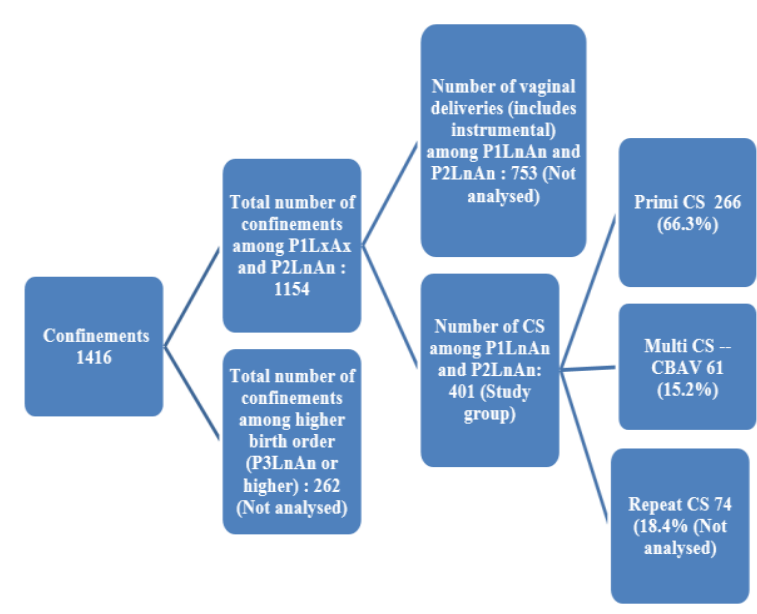

Figure 2: Distribution of confinements based on parity.

Figure 2 shows the proportion of primary CS in multigravidae, which amounted to $15.2 \%$.

As shown in Table 1, the various groups were tabulated based on whether the patient was antenatal registered with the hospital or if patient was transferred prior to the delivery outcome. Though there were more patients in the booked group, there was no significant difference in the outcomes between the two groups. Hence, booking status does not appear to influence outcomes in this study.

Table 2 compares the gestational age, birth weight and NICU admission rates between the two groups. The average gestational age at which CS was performed in the groups was 36.4 weeks. Since there is statistical significant difference between the groups, it is implied that the gestational age appears to have significant influence on the rate of CS between the groups of CS in primigravidae and CS in multigravidae. In Table 2 birth weight distribution is shown as per standard definition. There was no significant difference between the birth weights among the different groups. There was $11.4 \%$ rate of NICU admissions. However, there was no significant difference in the neonatal morbidity among the various groups. 
Table 1: Compares the various indications for the CS, booking status and previous abortions between the primipara group and the group of primary $\mathrm{CS}$ in multipara.

\begin{tabular}{|c|c|c|}
\hline Group & Multipara CS & Primi CS \\
\hline \multicolumn{3}{|l|}{ Indications } \\
\hline Fetal distress & $32(52.5 \%)$ & $142(53.4 \%)$ \\
\hline $\begin{array}{l}\text { Cephalopelvic } \\
\text { disproportion } \\
\text { (CPD) }\end{array}$ & $2(3.3 \%)$ & $23(8.6 \%)$ \\
\hline $\begin{array}{l}\text { Non-progress of } \\
\text { Labor }\end{array}$ & $3(4.9 \%)$ & $32(12.0 \%)$ \\
\hline Malpresentations & $7(11.5 \%)$ & $23(8.6 \%)$ \\
\hline $\begin{array}{l}\text { Deep Transverse } \\
\text { arrest }\end{array}$ & 0 & $15(5.6 \%)$ \\
\hline Placenta previa & $7(11.5 \%)$ & $3(1.1 \%)$ \\
\hline Abruptio placenta & $4(6.6 \%)$ & $6(2.3 \%)$ \\
\hline Others & $9.7 \%$ & $8.4 \%$ \\
\hline \multirow{2}{*}{\multicolumn{3}{|c|}{$\begin{array}{l}\text { Chi-square value of } 28.373, \mathrm{dF}-7, \mathrm{p} \text { value }<0.001 \text { and } \\
\text { association for each is significant } \\
\text { Booking status }\end{array}$}} \\
\hline & & \\
\hline Booked & $46(75.4 \%)$ & $169(63.5 \%)$ \\
\hline Transferred & $15(24.6 \%)$ & $97(36.5 \%)$ \\
\hline \multicolumn{3}{|c|}{$\begin{array}{l}\mathrm{P} \text { value } 0.0994 ; \text { Association is not statistically } \\
\text { significant. }\end{array}$} \\
\hline \multicolumn{3}{|c|}{ Number of previous abortions } \\
\hline 0 & $46(75.4 \%)$ & $223(83.8 \%)$ \\
\hline 1 & $10(16.4 \%)$ & $39(14.7 \%)$ \\
\hline 2 & $5(8.2 \%)$ & $2(0.8 \%)$ \\
\hline 3 & 0 & $2(0.8 \%)$ \\
\hline
\end{tabular}

Table 2: Compares the gestational age, birth weight and NICU admission rates between the two groups.

\begin{tabular}{|c|c|c|}
\hline & Multipara CS & Primi CS \\
\hline \multicolumn{3}{|c|}{ Gestational age (weeks) } \\
\hline $\begin{array}{l}\text { Preterm } \\
(<37 w k s)\end{array}$ & $12(19.7 \%)$ & $43(16.2 \%)$ \\
\hline $\begin{array}{l}\text { Term }(37- \\
40 w k s)\end{array}$ & $43(70.5 \%)$ & $181(68.0 \%)$ \\
\hline $\begin{array}{l}\text { Postterm } \\
\text { (>40wks) }\end{array}$ & $6(9.8)$ & $42(15.8 \%)$ \\
\hline \multicolumn{3}{|c|}{ (Pearson) Chi square-10.341, dF-2. P value 0.0057} \\
\hline \multicolumn{3}{|c|}{ Birth weight $(\mathrm{Kg})$} \\
\hline Severe LBW & $15(24.6 \%)$ & $46(17.3 \%)$ \\
\hline LBW & $11(18.0 \%)$ & $55(20.7 \%)$ \\
\hline Normal BW & $35(57.4 \%)$ & $165(62.0 \%)$ \\
\hline \multicolumn{3}{|c|}{ (Pearson) Chi square-4.397, dF-2, P value 0.1109.} \\
\hline \multicolumn{3}{|c|}{ NICU admission rates } \\
\hline Yes & $7(11.4 \%)$ & $13(4.8 \%)$ \\
\hline No & $54(88.6 \%)$ & $253(95.2 \%)$ \\
\hline $\mathrm{P}$ value equal & 714 & \\
\hline
\end{tabular}

Table 1 shows the various indications for the CS among the primipara group and the group of primary CS in multipara. CPD, non-progress of labor and DTA were less common in primary CS in multipara compared to primipara. Placenta previa and abruption placentae were more common in multipara compared to primipara. The indications appear to be different among the two groups. There was significantly higher number of abortions in those patients who were multipara compared to those who were primipara and the association was significant.

\section{DISCUSSION}

Primary CS refers to CS done in a patient who has not undergone prior CS. In a 6-year study conducted by Barber et al, a $10 \%$ increase in the overall CS rate was noted; the major increase was attributable to only primary $\mathrm{CS}^{3}$ Similarly, from India, Mittal et al reported an increase in primary CS rate from $69.03 \%$ to $72.62 \%$ over a ten-year period. ${ }^{4}$ These studies suggest that analysis of CS rates should focus on the primary CS rates. This comparative study analysed primary CS rates and related factors based on parity. While primigravidae form the majority, the focus of our study is the smaller group- multigravidae with previous vaginal delivery who undergo cesarean section (CBAV). Third para and beyond were excluded because of many variables, such as those with one cesarean followed by vaginal delivery etc, which prevent meaningful analysis.

The rate of primary CS in our study was $81.5 \%$. Of this, the contribution of multigravida was $15.2 \%$, higher than that of Sinnott et al who have reported a $4.5 \%$ rate in Ireland. ${ }^{5}$ Indian studies by $\mathrm{Rao} \mathrm{JH}$ et al and Desai et al have found the primary cesarean rate among multigravidae to be $10.2 \%$ and $29 \%$ respectively. ${ }^{6,7}$ Thus, the rate of primary cesarean among multigravidae without prior CS is heterogeneous.

In present study, almost $75 \%$ of the multigravidae who underwent CS were antenatally registered. Contrastingly, Desai et al found a higher rate among those who were unregistered and those who were transferred from a lower centre for management. This higher rate of CS among referred patients may be explained by mishandling of patients by inadequately trained health professionals, as opined by Shamshad et al. ${ }^{8}$ Similarly, the national data from Ireland has also observed a higher rate of emergency CS among multigravidae without prior CS, mainly among private clinics and delivery homes rather than in teaching hospitals. This is attributed to better equipped health care in teaching hospitals. ${ }^{5}$ It is important to note that data available regarding CS rates in India is from teaching hospitals and not from small private practitioners' clinics and maternity homes. In present study, there was a higher rate of CS among preterm patients. Other similar studies have either not analysed parameters based on gestational age or have excluded patients < 37weeks. . $^{5,9}$ In present study, the NICU admission rate was $11.4 \%$. The rate reported by Pruthwiraj et al was higher $(17 \%)$; while Prakash et al also reported a similar $11.3 \%$ rate. ${ }^{9}$ Sinnott et al reported 
an odds ratio of 3.82 for small-for-gestational age with elective CS in multipara without prior $\mathrm{CS}^{5}$

In present study, placenta previa and abruptio placentae were more common among multigravidae than primigravida. While the rate of antepartum haemorrhage in current study was $18.1 \%$, Pruthwiraj et al also found antepartum haemorrhage $(17 \%)$ as one of the leading indications for cesarean among multigravida. ${ }^{10}$ The study by Rao et al also found similar results (19.5\%). Sinnott et al also reported a much higher rate of abruptio placenta (odds ratio 42) and placenta previa (odds ratio 133), mainly with emergency $\mathrm{CS}$, and much lesser with elective CS. ${ }^{5}$ In present study, malpresentations were also more common in the multigravida group than the primigravida group. While it was $11.5 \%$ in present study, Desai et al found the same to be $17.4 \%$ and Prakash et al found it in $19.3 \%$. Sinnott et al also reported a much higher rate of malpresentations, and this proportion was higher among those with elective $\mathrm{CS} .^{5}$

Non-reassuring fetal status was the major indication (52\%) of CS in both primigravidae and multigravidae in the present study. Both Prakash et al and Desai et al found an approximate $25 \%$ of fetal distress in their study. Rao et al reported a $17 \%$ rate of fetal distress. Sethi et al analyzed indications differently and also found a much lesser rate of fetal distress as contributing to the cesarean sections. As correctly opined by Desai et al also, the notion that those women with previous vaginal delivery can be less vigilantly monitored as compared to a primigravidae is one to be condemned. In current study, cephalopelvic disproportion, non-progress of labor and deep transverse arrest was much less common in the multigravida group as the primigravida group. The number of abortions among multiparous patients was also higher than in the primipara group. Similar to our finding, Sinnott et al have also observed that those with higher number of abortions and those with previous fetal losses have a higher rate of $\mathrm{CS}^{5}$

In view of alarmingly high CS rate, researchers have focused on studying reasons for and ways to reduce the same. Robson's ten group classification for reporting CS rates classify patients into ten groups based on four patient characteristics namely parity, gestational age, spontaneous labor and presentation. Though this is now accepted as a standard method, it is difficult to apply clinically and only serves as a starting point for further analysis. ${ }^{11}$ To summarize, primary cesarean in multigravidae are an important contributor to the overall $\mathrm{CS}$ rates. The clinical profile and indications for $\mathrm{CS}$ in multigravidae are different from that of primigravidae. The main implication of this study for the clinician is that multigravida patients should be cared for in ways uniquely different from primigravidae patients, and their care during labor cannot be trivialized.
The main limitations of this study include the retrospective nature of the study and a small sample size. Medical high-risk factors which may contribute to a higher CS rate among multigravidae were not analysed. Further prospective studies with larger sample size may be needed to draw stronger conclusions on this topic.

Funding: No funding sources

Conflict of interest: None declared

Ethical approval: The study was approved by the Institutional Ethics Committee

\section{REFERENCES}

1. Betrán AP, Ye J, Moller AB, Zhang J, Gülmezoglu $\mathrm{AM}$, Torloni MR. The increasing trend in cesarean section rates: global, regional and national estimates: 1990-2014. PLoS One Public Library of Science; 2016;11(2):e0148343.

2. WHO statement on cesarean sections. Available at http://apps.who.int/iris/bitstream/10665/161442/1/W HO_RHR_15.02_eng.pdf

3. Barber EL, Lundsberg LS, Belanger K, Pettker CM, Funai EF, Illuzzi JL. Indications contributing to the increasing cesarean delivery rate. Obstet Gynecol. 2011;118(1):29-38.

4. Mittal S, Pardeshi S, Mayadeo N, Mane J. Trends in cesarean delivery: rate and indications. J Obstet Gynaecol India. 2014;64(4):251-4.

5. Sinnott SJ, Brick A, Layte R, Cunningham N, Turner MJ. National variation in caesarean section rates: a cross sectional study in Ireland. PLoS One. 2016;11(6):e0156172.

6. Rao JH, Rampure N. Study of primary cesarean section in multiparous women. J Evol Med Dental Sci. 2013;2(24):4414-18.

7. Desai E, Leuva H, Leuva B, Kanani M. A study of primary cesarean section in multipara. Int J Reprod Contracept Obstet Gynecol. 2013;2(3):320-4.

8. Shamshad. Factors leading to increased cesarean section rate. Gomal J of Med Sci. 2008;6(1):1-6.

9. Prakash SA, Vikram A, Rajagopal K, Lavanya PS. Primary cesarean section in mulitgravidas. Int $\mathbf{J}$ Reprod Contracept Obstet Gynecol. 2016;5:3849-52.

10. Pruthwiraj S, Vijayalaxmi S, Shailaja G, Bodhare T, Devi S. A study of primary cesarean section in multigravidae. Perspectives Med Res. 2014;2(2):3-7.

11. Yadav RG, Maitra N. Examining cesarean delivery rates using the Robson's ten-group classification. J Obstet Gynecol India. 2016;66(S1):1-6.

Cite this article as: Prasad MS, Chauhan AR.

Primary cesarean section in multigravidae: a case control study. Int J Reprod Contracept Obstet Gynecol 2017;6:2948-51. 